\title{
Publisher Correction: Interlayer excitons in a bulk van der Waals semiconductor
}

\author{
Ashish Arora (1) 1, Matthias Drüppel ${ }^{2}$, Robert Schmidt (1) ${ }^{1}$, Thorsten Deilmann (D) 2,3, Robert Schneider ${ }^{1}$, \\ Maciej R. Molas ${ }^{4}$, Philipp Marauhn², Steffen Michaelis de Vasconcellos (1D ${ }^{1}$, Marek Potemski ${ }^{4}$, \\ Michael Rohlfing ${ }^{2} \&$ Rudolf Bratschitsch (i) ${ }^{1}$
}

Nature Communications 8:639 doi:10.1038/s41467-017-00691-5; Article published online: 21 September 2017

In the PDF version of this article, Equation 1 is missing an epsilon at the beginning. The correct version of Equation 1 is below. The HTML version of the paper was correct from the time of publication.

$$
\epsilon(E)=\left(n_{\mathrm{b}}+\mathrm{i} k_{\mathrm{b}}\right)^{2}+\frac{A}{E_{0}^{2}-E^{2}-\mathrm{i} \gamma E} .
$$

Published online: 17 November 2017

Open Access This article is licensed under a Creative Commons Attribution 4.0 International License, which permits use, sharing, adaptation, distribution and reproduction in any medium or format, as long as you give appropriate credit to the original author(s) and the source, provide a link to the Creative Commons license, and indicate if changes were made. The images or other third party material in this article are included in the article's Creative Commons license, unless indicated otherwise in a credit line to the material. If material is not included in the article's Creative Commons license and your intended use is not permitted by statutory regulation or exceeds the permitted use, you will need to obtain permission directly from the copyright holder. To view a copy of this license, visit http://creativecommons.org/licenses/by/4.0/.

(c) The Author(s) 2017

\footnotetext{
${ }^{1}$ Institute of Physics and Center for Nanotechnology, University of Münster, Wilhelm-Klemm-Strasse 10, 48149 Münster, Germany. ${ }^{2}$ Institute of Solid State Theory, University of Münster, Wilhelm-Klemm-Strasse 10, 48149 Münster, Germany. ${ }^{3}$ Center for Atomic-Scale Materials Design (CAMD), Department of Physics, Technical University of Denmark, DK-2800 Kongens Lyngby, Denmark. ${ }^{4}$ Laboratoire National des Champs Magnétiques Intenses, CNRS-UGA-UPSINSA-EMFL, 25 rue des Martyrs, 38042 Grenoble, France. Ashish Arora and Matthias Drüppel contributed equally to this work. Correspondence and requests for materials should be addressed to R.B. (email: Rudolf.Bratschitsch@uni-muenster.de)
} 